\title{
Prognosis Value of Two Gravity Scores in Patients Admited to the Intensive Care Unit at University Hospital of Parakou in Benin
}

\section{Blaise Adelin Tchaou*, Nvènonfon Charles Frédéric Tchégnonsi, Hervé Philippe Minsili Bikolo, Patrick Stéphane Kouomboua Mfin, Martin Chobli}

Service d'Anesthésie-Réanimation et des Urgences, Centre Hospitalier Universitaire et Départemental du Borgou/Alibori, Parakou, Benin

Email: ^tchblaise@yahoo.fr

How to cite this paper: Tchaou, B.A., Tchégnonsi, N.C.F., Bikolo, H.P.M., Mfin, P.S.K. and Chobli, M. (2020) Prognosis Value of Two Gravity Scores in Patients Admited to the Intensive Care Unit at University Hospital of Parakou in Benin. Open Journal of Anesthesiology, 10, 144-156.

https://doi.org/10.4236/ojanes.2020.104013

Received: March 17, 2020

Accepted: April 27, 2020

Published: April 30, 2020

Copyright $\odot 2020$ by author(s) and Scientific Research Publishing Inc. This work is licensed under the Creative Commons Attribution International License (CC BY 4.0).

http://creativecommons.org/licenses/by/4.0/

(c) (i) Open Access

\begin{abstract}
Introduction: The gravity of the clinical state of the patient of intensive care is linked to the existence of one or several lesions and visceral defaults putting its forecast into play. Objective: To determine the prognosis value of two general graveness' scores of patients admitted to intensive care at University Hospital of Parakou in Benin. Patients and Methods: Descriptive and analytical observational study data were collected from March $1^{\text {st }}$ to June $30^{\text {th }}, 2017$. The SAPS II and APACHE II were calculated during first 24 hours of hospitalization to assess the clinical graveness and predict patient's mortality. Results: We enrolled 185 patients representing $89.37 \%$ of admissions, majority were men $(63.78 \%)$. Mean age was $38.89 \pm 17.92$ years (16 to 99 ), mean of hospitalization duration was $4.36 \pm 2.2$ days. Neurological failure was the most common disorder observed (58.37\%). Mean SAPS II and APACHE II were $29.54 \pm$ 19.04 and $14.24 \pm 10.49$ respectively. Mean predicted mortality of SAPS II and APACHE II was $19.12 \pm 5.05$ and $25.69 \pm 5.00$ respectively. The mortality rate was $25.95 \%$ and increased with severity scores. The sensibility of APACHE II and SAPS II score was $72.90 \%$ and $66.70 \%$ respectively. SAPS II score was found to be more specific (85.40\%) than APACHE II (80.03\%). Conclusion: Those severity patient scores accurately predicted the prognosis of patients in intensive care unit and should be integrated into our practice.
\end{abstract}

\section{Keywords}

Indications of Gravities, Prognosis, Mortality, Intensive Care 


\section{Introduction}

The severity of a patient's clinical condition is related to the existence of one or more lesions responsible for visceral failures which can put into play patient's vital prognosis. Its management requires continuous monitoring of vital functions and the use of replacement methods such as hemodynamic support, artificial ventilation and even renal assistance [1] [2].

The admission of a patient in intensive care and the implementation of resuscitation manoeuvres are the responsibility of an anaesthetist/resuscitator who will decide after assessing the seriousness of the patient's clinical condition. This assessment has led learned societies to develop various scoring systems, particularly severity scores, which have made it possible to assess the severity of a patient's clinical condition on the one hand, and to propose systems for allocating or directing resources in order to contribute to clinical and therapeutic decision making on the other hand [3]. The most used general multi-purpose severity scores are: IGS II (Simplified Severity Index 2), APACHE II (Acute Physiologic and Chronic Health Evaluation 2), MPM (Mortality Probability Model) and SOFA (Sequential Organ Failure Assessment Score). Severity indices have seen their use widely popularized in intensive care units of developed countries in the early 1980s [4]. It has contributed in improving management and reducing mortality in general [5].

In Africa, on the other hand, the situation is more critical, because technological progresses are still non-existent. Delay in consultation, lack of qualified human resources and lack of adequate equipment are the causes of mortality still high in intensive care units [6]. Despite this high mortality, little work in Africa has shown interest in the adoption of a severity score adapted to our working conditions in order to assess the severity and predict patient's prognosis.

In Benin and in particular Cotonou in 2014, Lokossou et al. evaluated the usefulness of severity scores in intensive care units [7]. However, to our knowledge, there is no data on the assessment of prognostic value of these scores, reason why we conducted this study, whose objective was to determine the prognostic value of two general severity scores (IGS II and APACHE II) on patients admitted to intensive care units at the Parakou University Hospital in Benin.

\section{Patients and Methods}

\subsection{Study Framework}

The intensive care unit of the University Hospital of Parakou in Benin was used as the study setting. It is a 24-hour functional unit with 13 beds, 4 of which are equipped with multiparameter scopes with two intensive care respirators.

\subsection{Type and Period of Study}

It was an observational study with a descriptive and analytical aim with prospective data collection carried out over a period of 4 months, from the $1^{\text {st }}$ of March 2017 to the $30^{\text {th }}$ of June 2017. 


\subsection{Patients}

Our study population consisted of patients of more than 16 years of age who were hospitalized in intensive care for at least two (02) hours having given their free and informed consent or of the family representative. All patients younger than 16 years of age or who had been in the unit for less than two (02) hours (death, transfer) were not included in the study. An informed consent form was filled and signed by the patients or a family representative. The study was conducted after obtaining an authorization from the local ethics and biomedical research committee of the University of Parakou. An exhaustive recruitment of patients fulfilling the inclusion criteria was carried out and data were collected by the means of a questionnaire filled after reviewing medical records and conducting clinical and paraclinical exams.

The independent variables studied were sociodemographic (age, sex), clinical (type of admission, history, vegetative constants, visceral defects, Glasgow score), paraclinical (blood count and formula, azotemia/creatininemia, liver transaminases, blood cramps), progressive (good or complicated) and prognostic (alive/dead).

The dependent variables were represented by the two general severity scores selected for the study (IGS II, APACHE II). Patients were classified according to disease category. Each of the scores were scored for our patients on their admission and then calculated using the software Médicalcul version 1.32 [8], which gave us score values, as well as the predicted mortality when available. These were:

- IGS II (Simplified Severity Index II): a simplified severity assessment system created by Le Gall et al. [9]. It is a questionnaire with 12 variables (age, type of admission (medical, urgent surgical or programmed) and underlying diseases (AIDS, metastatic cancer and hematological disease)). Score scoring is done during the first 24 hours and only the most abnormal ones observed are considered for scoring. The score obtained varies from 0 to 163 points of which 116 points for the 12 variables, 26 points maximum for Glasgow, 17 points maximum for age, 30 points maximum for chronic diseases.

- The APACHE II (Acute Physiology and Chronic Health Evaluation II) score was developed in 1985 on the basis of 12 variables evaluated during the first 24 hours of hospitalisation in intensive care [10]. Each variable is evaluated and quoted with a value ranging from 0 (normality zone) to 4 (most abnormal value). Biological data impossible to mesure (arterial $\mathrm{pH}$ ) which doesn't prevent the score from being scored; a 3\% margin of error set by the authors of the score for each of the missing variables and considered normal.

\subsection{Statistical Analysis}

The qualitative variables were expressed in terms of frequency and percentage. Quantitative variables were expressed in terms of mean plus or minus standard deviation from mean. For each of the IGS II and APACHE II scores, the Receiver Operating Caracteristic (ROC) analysis allowed to split patients into two severity groups from the threshold value obtained. From the determined thresholds, 
patients were classified into two groups: severe and less severe state. The calibration of each score was evaluated using decision matrix analysis (threshold values set a priori) to compare observed and predicted results to a decision criterion of 1 (a calibration greater or less than 1 was bad; meanwhile, it was excellent if equal to 1 ). By the way, the strength of mortality prediction of each score was determined according to the indices obtained. The main variables associated with mortality in univariate analysis, including severity scores (dichotomized), were simultaneously introduced into a logistic regression model by performing successive iterations of the stepwise descending type. The strength, meaning and stability of the association were estimated using Odds ratios with their 95\% confidence interval. A p $<0.05$ was considered as statistically significant. All collected data have been entered, processed and analyzed with the software Epi Info v7.1.1.14 and XLSTAT version 2017. The tests used were the ANOVA test, the Fisher's exact test or the Pearson's Chi-2 $\left(\chi^{2}\right)$ test.

\section{Results}

\subsection{Socio-Demographic Data}

During the study period, 207 patients were admitted to intensive care. We collected 185 patients representing $89.37 \%$ of the admissions of which $63.78 \%$ were male (sex ratio: 1.76). The mean age of the patients was $38.89 \pm 17.92$ years with extremes of 16 and 99 years. The most represented age group patients were those aged 16 to 25 years (27.03\%). The self-employed were the most represented (60\%). Unemployed patients numbered $31(16.76 \%)$, followed by pupils and students $(26 ; 14.05 \%)$ and employees $(17 ; 9.19 \%)$. Table 1 shows the distribution of patients according to age, sex and profession.

\subsection{Clinical and Paraclinical Data}

Medical pathologies were the main type of admission to intensive care (50.27\%). Other reasons for admission were urgent surgery (45.41\%) and scheduled surgery (4.32\%). In our series 71 patients (38.38\%) had at least one pathological history. The pathologies identified were hypertension (16.22\%), surgery (12.43\%), diabetes (5.41\%), HIV immunosuppression (2.70\%), and metastatic cancer (1.62\%). The reasons for hospitalization identified were varied. Traumatic pathologies came first $(26.49 \%)$. Among them, cranioencephalic trauma (TCE) was the most frequent traumatic pathology (59.18\%). Table 2 shows the distribution of patients by reason for admission.

The scoring of the scores required the search for the various visceral failures. The visceral failures observed were: neurological failure (58.38\%), respiratory failure (49.19\%), renal failure (41.08\%), hepatic failure (12.43\%), hematological failure (10.81\%) and cardiocirculatory failure (9.19\%).

The ROC (Receiver Operating Caracteristic) analysis allowed to find the thresholds of severity of the IGS II and APACHE II scores (Figure 1 and Figure 2).

Table 3 shows the distribution of patients according to the threshold values, mean and extreme values of severity scores. 
Table 1. Distribution of patients according to age, sex and profession.

\begin{tabular}{|c|c|c|}
\hline & Number & Percentage \\
\hline & Sex & \\
\hline Male & 118 & 63.78 \\
\hline Feminine & 67 & 36.22 \\
\hline \multirow[t]{2}{*}{ Total } & 185 & 100 \\
\hline & Age & \\
\hline$[16-25]$ & 50 & 27.03 \\
\hline [26 - 35] & 42 & 22.70 \\
\hline$[36-45]$ & 32 & 17.30 \\
\hline [46 - 55] & 27 & 14.59 \\
\hline$[56-65]$ & 18 & 9.73 \\
\hline$\geq 66$ & 16 & 8.65 \\
\hline Total & 185 & 100 \\
\hline \multicolumn{3}{|c|}{ Profession } \\
\hline Self-employed & 111 & 60 \\
\hline Unemployed & 31 & 16.76 \\
\hline Pupils and students & 26 & 14.05 \\
\hline Employees & 17 & 9.19 \\
\hline Total & 185 & 100 \\
\hline
\end{tabular}

Table 2. Distribution of patients according to the reason for admission.

\begin{tabular}{ccc}
\hline & Number & Percentage \\
\hline Traumatic pathologies & 49 & 26.49 \\
Cranioencephalic traumas & 29 & 15.68 \\
Other traumas & 20 & 10.81 \\
Hypertensive emergencies & 43 & 23.25 \\
Cerebrovascular accidents & 30 & 16.22 \\
Eclampsia & 13 & 7.03 \\
Post-surgical Care & 42 & 22.70 \\
Septic states & 25 & 13.51 \\
Envenimation and intoxication & 13 & 7.03 \\
Envenimation by snake bites & 10 & 5.41 \\
Intoxication & 3 & 1.62 \\
Diabetic Comas & 6 & 3.24 \\
Metastatic tumor & 3 & 1.62 \\
Chronic kidney failure & 3 & 1.62 \\
Acute pancreatitis & 1 & 0.54 \\
\hline
\end{tabular}


Courbe ROC / Test / AUC $=0,819$

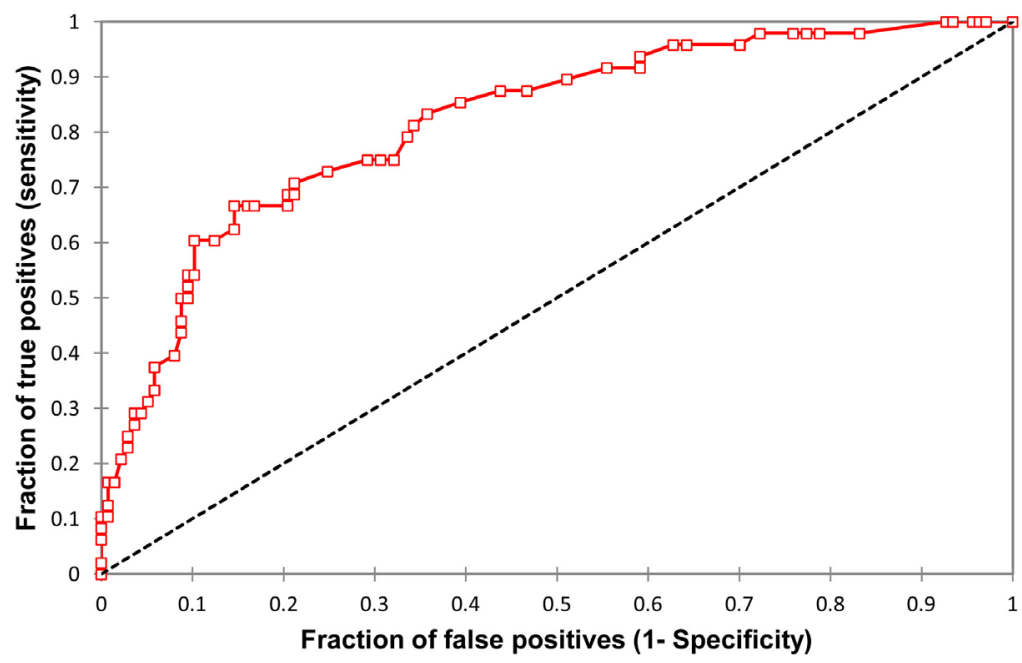

Figure 1. ROC curve of the IGS II score.

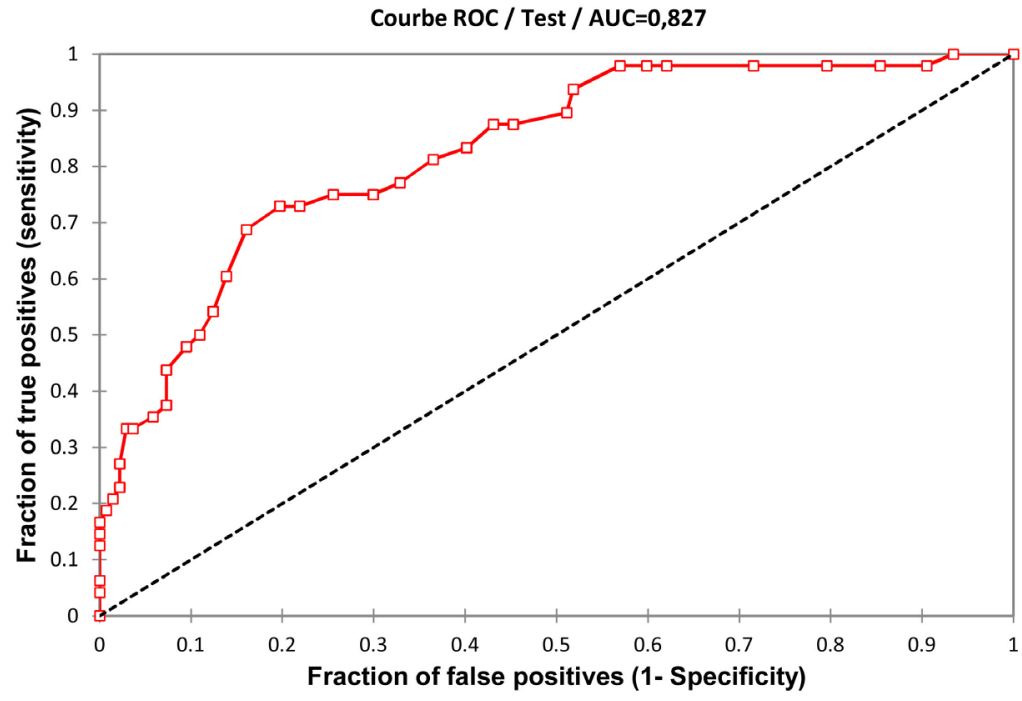

Figure 2. ROC curve of the APACHE II score.

Table 3. Distribution of patients according to threshold values, means and extreme values of severity scores.

\begin{tabular}{ccccc}
\hline & Number & $\%$ & Average & IC $^{*}(95 \%)$ \\
\hline Slight gravity $(<40)$ & 133 & 71.89 & & \\
Severe Patients $(\geq 40)$ & 52 & 28.11 & 29.54 & {$[10.50-48.58]$} \\
Total & 185 & 100 & & \\
\hline Slight gravity $(<19)$ & & APACHE II & & \\
Severe Patients $(\geq 19)$ & 123 & 66.49 & & \\
Total & 62 & 33.51 & 14.24 & \\
\hline
\end{tabular}




\subsection{Evolutionary and Prognostic Data}

The length of stay in intensive care ranged from 04 hours to 48 days with a mean of $4.36 \pm 2.2$ days. 48 deaths (25.95\%) were recorded, the mean age of the death patients was $46.10 \pm 19.44$ years. In our series $62.5 \%$ deaths had occurred within the first 48 hours of admission, they were hospitalized for a medical (50.27\%) or surgical (49.73\%) pathology. At least one visceral failure had been found in $97.91 \%$ of death patients.

\subsection{Mortality and Severity Scores}

Regarding mortality and IGS II score, $66.66 \%(\mathrm{n}=32)$ of deaths occurred to those with an IGSII score $\geq 40$ (severe cases) versus $33.34 \%$ (16) of those with an IGS II score $<40$ (light severity). For IGS II $\geq 76$ there were no survivors. The average IGS II scores for the death and surviving patients were $46.04 \pm 19.30$ years and $23.75 \pm 15.23 \mathrm{p}=0.00$, respectively.

Regarding the APACHE II score, $72.91 \%$ (35) of the death patients had an APACHE II $\geq 19$ versus $27.09 \%$ (13) of deaths on those with an APACHE II $<19$. For APACHE II $\geq 35$ there were no survivors. The means of the APACHE II score for the death and for the survivors were $23.60 \pm 10.40$ and $10.96 \pm 8.35 \mathrm{p}<$ 0.001 , respectively.

\subsection{Predicted Mortality (PM) by IGS II and APACHE II Scores}

The IGS II and APACHE II severity scores allowed to calculate the Predicted Mortality (PM) of our patients (MP-IGS II and MP-APACHE II) and the obtained results are reported in Table 4. Distribution of patients according to the Predicted Mortality by IGS II and APACHE II scores.

\subsection{Performance Analysis of Severity Scores IGS II, APACHE II}

Table 5 shows the performance analysis of the IGS II, APACHE II severity scores.

\subsection{Univariate and Multi-Variate Statistical Analysis of IGS II, APACHE II Severity Scores and Death}

Table 6 presents the results of the univariate analysis between IGS II, APACHE II and death.

Table 4. Distribution of patients according to the Predicted Mortality by IGS II and APACHE II scores.

\begin{tabular}{ccccc}
\hline & \multicolumn{4}{c}{ Predicted Mortality } \\
\cline { 2 - 5 } & \multicolumn{2}{c}{ IGS II } & APACHE II \\
\cline { 2 - 5 } & Average & p & Average & p \\
\hline Global & $19.12 \%$ & 0.00 & $25.69 \%$ & 0.00 \\
Surviving Patients & $11.55 \%$ & & $18.05 \%$ & \multirow{2}{*}{0.00} \\
Death patients & $40.74 \%$ & 0.00 & $47.49 \%$ & \\
Severe Patients & $54.56 \%$ & & $55.50 \%$ & 0.00 \\
Light severity Patients & $5.27 \%$ & 0.00 & $10.66 \%$ & \\
\hline
\end{tabular}


Table 5. Performance analysis for the 3 severity scores used.

\begin{tabular}{ccc}
\hline & IGS II & APACHE II \\
\hline Sensitivity & $66.70 \%$ & $72.90 \%$ \\
Specificity & $85.40 \%$ & $80.03 \%$ \\
OR & 1.02 & 1.04 \\
p & 0.39 & 0.38 \\
AUC-ROC \pm SD & $0.82 \pm 0.08$ & $0.83 \pm 0.08$ \\
Youden Index & 0.52 & 0.53 \\
\hline
\end{tabular}

$\mathrm{SD}^{* *}$ : Standard deviation.

Table 6. Logistic regression model between IGS II, APACHE II scores and death.

\begin{tabular}{|c|c|c|c|c|c|c|c|}
\hline & \multicolumn{2}{|c|}{ Survival modality } & \multirow{2}{*}{ Total } & \multirow{2}{*}{$\begin{array}{c}\text { OR } \\
\text { (IC 95\%) }\end{array}$} & \multirow{2}{*}{$\mathrm{p}$} & \multirow{2}{*}{$\begin{array}{l}\text { OR }_{\text {ajusté }} \\
\text { (IC 95\%) }\end{array}$} & \multirow{2}{*}{$\mathrm{p}$} \\
\hline & Deceased & Alive & & & & & \\
\hline APACHE II $\geq 19$ & $\begin{array}{c}33 \\
(60.00 \%)\end{array}$ & $\begin{array}{c}22 \\
(40.00 \%)\end{array}$ & 55 & 1 & & 1 & \\
\hline APACHE II $<19$ & $\begin{array}{c}15 \\
(11.54 \%)\end{array}$ & $\begin{array}{c}115 \\
(88.46 \%)\end{array}$ & 130 & $\begin{array}{c}11.5 \\
{[5.37 ; 24.64]}\end{array}$ & $10^{-5}$ & $\begin{array}{c}4.15 \\
{[1.44 ; 11.98]}\end{array}$ & 0.0006 \\
\hline IGS II $\leq 40$ & $\begin{array}{c}30 \\
(60.00 \%)\end{array}$ & $\begin{array}{c}20 \\
(40.00 \%)\end{array}$ & 50 & 1 & & & \\
\hline IGS II $>40$ & $\begin{array}{c}18 \\
(13.33 \%)\end{array}$ & $\begin{array}{c}117 \\
(86.67 \%)\end{array}$ & 135 & $\begin{array}{c}9.75 \\
{[4.59-20.69]}\end{array}$ & $10^{-5}$ & $\begin{array}{c}2.98 \\
{[1.10 ; 8.04]}\end{array}$ & 0.0198 \\
\hline TOTAL & 48 & 137 & 185 & & & & \\
\hline
\end{tabular}

OR: Odds ratio IC 95\%: 95\% confidence interval.

\section{Discussion}

\subsection{Clinical and Paraclinical Data}

\section{Intake type}

In our series, we had as many medical admissions as we have surgical admissions. However, among the reasons for surgical admissions, surgical emergencies predominated (91.30\%). Our results are different from those reported by Tchoua et al. in 1999 in Gabon, who reported a predominance of medical admissions (61.57\%) [11] in contrast to Diouf et al. in Senegal in 2011 and Iteke et al. in Congo in 2014, who reported a predominance of surgical admissions in the same proportions of $60 \%$ [12] [13]. This high frequency of surgical emergencies found in our study could be explained by the increasing number of traffic accidents responsible for serious injuries, particularly cranioencephalic trauma, and the delay in consulting of certain patients suffering from infectious or parasitic medical pathologies which, in the absence of early diagnosis and treatment, evolve towards surgical complications, particularly peritonitis and occlusions.

\subsection{Background}

Our findings are similar to those of other African authors. Indeed, Lokossou et al. reported in a study conducted in Cotonou in 2014 that $35.7 \%$ of patients had 
a pathological antecedent [7]. Concerning the pathologies found, high blood pressure and diabetes predominated in many studies and specifically Lokossou et al. in Cotonou, Dia et al. in Senegal, also found high blood pressure as the main pathological antecedent with respective frequencies of $54.5 \%$ and $20.2 \%$ [7] [14]. These results are corroborated by WHO's reports who makes hypertension a public health problem [15].

\subsection{Visceral Failures}

In our study, more than $75 \%$ of patients had at least one visceral failure at admission. Wade et al. found that $50.4 \%$ of patients had experienced visceral failure on admission to their series in 2011 in Senegal [4]. Neurological failure was the most common in our study, followed by respiratory failure. Our results are comparable to those of Wade et al. [4] in Senegal, who found neurological failure to be the most frequent (30.5\%), followed by respiratory failure (28.8\%). In contrast, Tchoua et al. [11] in 1999 in Gabon found respiratory failure to be the most common in $40 \%$ of cases, followed by neurological failure (21\%). The high number of cranioencephalic traumas, high blood pressure including stroke, diabetic comas and eclampsia could justify the predominance of neurological failure in our series.

\subsection{Reason for hospitalization}

Traumatic pathologies represented the main reason for hospitalization in our series and were dominated by cranioencephalic traumas. Our results are corroborated by the results of other studies around the world [16] [17]. The predominance of traumatic pathologies could be explained by the increase in the number of road accidents resulting from the non-respect of basic traffic regulations and the poor state of the road infrastructure and parking. High blood pressure emergencies constituted the second major group of reasons for hospitalization followed by severe patients admitted for post-surgery care. Similar results were found by Diouf et al. [12] in 2011 in Senegal (29.42\% of cases). We can link this high rate of patients admitted for post-surgery care in our intensive care unit to the high number of surgical emergencies, particularly visceral and trauma emergencies.

\subsection{Evolving and Prognostic Data}

\section{Length of stay}

The average length of stay in our series was relatively short. This observation is comparable to those made by some authors who reported an average length of stay ranging from 4 to 10 days [18] [19]. So, in order to reduce the risk of infections related to intensive care and the unfavourable evolution of patients after surgery, we opt for aggressive nature of drug management, in especially by double antibiotic therapy (even triple antibiotic therapy) and rigorous monitoring, elements that contribute to the fast improvement of patients' clinical condition and their discharge from intensive care. 


\section{Mortality}

The objectified mortality in our series remains high despite the progress made in patient management compared to those reported in countries with a high technical plateau. In France, Jungfer et al. reported 18\% of mortality in 2008 [20]. Grégoire et al. in Belgium and Sik et al. in Tunisia had respectively found a mortality rate of $14.7 \%$ and $16 \%$ in their series in 2017 [21] [22]. On the other hand, our mortality rate appears to be lower compared to other African series. Diouf et al. in Senegal in 2011, Iteke et al. in Congo in 2014, and Lokossou et al. in Cotonou in 2014 had objectified mortality rates of 32.7\%, 32.7\% and 60.5\% respectively [7] [12] [13]. In general, death rates in intensive care units are higher than in other services worldwide. This is explained by the severity of the clinical condition of patients on admission, often in relation to the multivisceral failures linked to the long consultation time limit.

\subsection{Mortality and Severity Scores}

\section{The IGS II system}

Mortality increased significantly with a high IGS II score $\mathrm{p}<0.001$. These results are similar to those reported by other authors [23] [24]. Among the death patients, $60 \%$ had an IGS II score $\leq 40$ (light severity) against $13.33 \%$ of deaths in severe patients (IGS II $>40) \mathrm{p}<0.001$. There was a significant statistical difference between the mean IGS II values among survivors $(23.75 \pm 15.23)$ and those who died $(46.04 \pm 19.30) \mathrm{p}<0.001$. An APACHE II score $\geq 19$ was significantly associated with death $\mathrm{OR}=11.5[5.37 ; 24.64] \mathrm{p}=10^{-5}$. An IGS II score $>$ 40 was a risk factor significantly associated with death in both univariate and multivariate analysis by logistic regression with odd ratio and $\mathrm{P}$ value respective of $\mathrm{OR}=9.75[4.59 ; 20.69] \mathrm{p}=10^{-5}$, adjusted $\mathrm{OR}=3.22[1.20 ; 8.61] \mathrm{p}=0.0198$. The IGS II score had a standardized report of overall mortality (SMR) of 1.35 (19.12\% predicted mortality for $25.95 \%$ observed mortality); indicating a poor overall adjustment of the score in our study. Deaths were relatively well estimated by the IGS II in patients of light severity with an SMR of 1.12 (12.03\% of observed mortality for $5.27 \%$ of predicted mortality); in severe patients, on the other hand we had an overestimation of death by the score with an SMR of 2.28 (54.56\% predicted mortality for $61.53 \%$ observed mortality). These results reflect a poor calibration of the IGS II score in our study, resulting either from poor management, poor IGS II rating (by default), or simply from an inadequacy of the IGS II score for these defined severity groups. Wade et al. [4] [11] in 2011 in Senegal had also found a poor calibration of the IGS II score in their study. The area under the ROC curve had shown a good discrimination capacity of $0.82 \pm$ 0.04 with a sensitivity of $66.70 \%$ and a specificity of $85.40 \%$. The found Youden index (0.52) demonstrated the effectiveness of IGS II in predicting mortality in our study. Several authors also corroborated our results. This is the case of Le Gall et al. in 1993, who found an AUC-ROC of 0.86 in the initial sample of 13,152 patients who enabled the validation of the IGS II score [25]. 


\section{The APACHE II score}

Mortality increased significantly with a high APACHE II score $\mathrm{p}<0.001$. These observations are similar to those of literature [26] [27]. Among the death patients, $60 \%$ had an APACHE score $\geq 19$ (severe patient) against $11.54 \%$ among those with an APACHE II score $<19$ (light severity) $\mathrm{p}<0.001$. In our series, the APACHE II mean points were significantly different in the death as in the alive with respectively $23.60 \pm 10.40$ versus $10.96 \pm 8.35 \mathrm{p}=0.00$. An APACHE II score $\geq 19$ was significantly associated with death $\mathrm{OR}=11.5[5.37 ; 24.64] \mathrm{p}<$ $10^{-5}$. The standardized mortality ratio (SMR) of the APACHE II score showed of its good overall adjustment in our study, with a value of 1.01 (25.69\% predicted mortality for $25.95 \%$ observed mortality). There was an excellent ratio for the different severity groups with SMR values of 0.99 for light severe cases $(10.66 \%$ predicted mortality for $10.57 \%$ observed mortality) and 1.05 for severe cases (55.50\% predicted mortality for $58.64 \%$ observed mortality). These results show a good calibration of the APACHE II system in our study and are in line with other work carried out elsewhere. The area under the ROC curve showed a good discrimination capacity of $0.83 \pm 0.08$ of the score. It also demonstrated its efficiency in our series with a sensitivity of $72.90 \%$, a specificity of $80.03 \%$ and the Youden index of 0.53. APACHE II had the best discrimination as well as the best calibration and therefore has demonstrated its ability to predict mortality sufficiently well.

\subsection{Limit of the Study}

APACHE II asserts its validity as a predictive tool in our unit before the IGS II. We suggest extending this prospective study to a larger sample, with a view to validating this model in countries with limited resources such as ours.

\section{Conclusion}

The prognostic value of severity scores in intensive care is demonstrated through the results of our study. These severity scores accurately predict the prognosis of patients in the intensive care unit and should be integrated into our practice in order to better appreciate the severity of each patient's clinical condition, a factor that conditions the initiation of resuscitation maneuvers for adequate management.

\section{Conflicts of Interest}

The authors declare that they have no conflicts of interest in relation to this article. The study was carried out in a developing country and without external financial support.

\section{References}

[1] Décret $\mathrm{n}^{\circ}$ 2002-465 du 5 avril 2002 relatif aux établissements de santé publics et privés pratiquant la réanimation et modifiant le code de la santé publique (deuxième partie: Décrets en Conseil d'Etat) Articles R. 712-90 à R. 712-95 JÜRF Nº 82 du 7 avril 2002: 6187. http://www.journal-officiel.gouv.fr 
[2] Groupe de travail SFAR, CNERM, CMRUHEUF, SNMRHP et le GFRUP, SNPHAR, SNMARHNU, SPAR et le CFAR (1996) Le manifeste pour la réanimation. Réanimation et Urgences, 5, 709-711.

[3] Deuxième conférence de consensus européenne en réanimation et médecine d'urgence. Facteurs pronostiques chez les malades de réanimation. 09 au 10 Décembre 1993. Maison de la chimie Paris (France-2001), 8 p.

https://urgences-serveur.fr/IMG/pdf/Facteurs_pronostiques_chez_les_malades_de_ re_uanimation.pdf

[4] Wade, K.A., Diallo, A., Beye, S.A., Niang, E.H., Diop, M. and Diatta, B. (2011) Evaluation de l'utilisation des scores de gravité dans le service de réanimation de l'hôpital d'instruction des armées principal de Dakar. Revue Africaine d Anesthésiologie et de Médecine dUrgence, 16, 12-17.

[5] Knauss, W.A., Wagner, D.P., Zimmerman, J.E. and Drapper, E.A. (1993) Variations in Mortality and Length of Stay in Intensive Care Units. Annals of Internal Medicine, 118, 753-761. https://doi.org/10.7326/0003-4819-118-10-199305150-00001

[6] Ouedraogo, N., Niakara, A., Simpore, A., Barro, S., Ouedraogo, H. and Sanou, J. (2002) Soins intensifs en Afrique: expérience des deux premières années d'activité' du service de réanimation du centre hospitalier national de Ouagadougou (Burkina Faso). Cahier d'études et de recherches francophones, santé, 12, 375-382.

[7] Lokossou, T.C., Sama, H.D., Bawa, B.M., Chinoun, Y., Tchegnonsi, C., Assouto, P., Zoumenou, E., Tomta, K., Hémou, P. and Chobli, M. (2014) Ahouangbévi. Utilité des scores de gravité en unités de soins intensifs au Bénin. Médecine d'Afrique Noire. Numéro spécial SARANF, 61, 33-37.

[8] Mignard, P. (2017) Médicalcul Version 1.32, [en ligne]. http://micromeg.free.fr

[9] Le Gall, J. and Alberti, C. (2014) Indices de gravité et applications en réanimation. Encyclopédie Médico-Chirurgicale 36-700-A-10.

[10] Knaus, W.A., Draper, E.A., Wagner, D.P. and Zimmerman, J.E. (1985) APACHE II: A Severity of Disease Classification System. Critical Care Medicine, 13, 818-819. https://doi.org/10.1097/00003246-198510000-00009

[11] Tchoua, R., Vemba, A., Taty Koumba, C. and Ngaka, Nsafu, D. (1999) Gravité des maladies de réanimation à la Fondation Jeanne Ebori de Libreville. Médecine d Afrique Noire, 46, 495-499.

[12] Diouf, E., Leye, P.A., Bah, M.D., Ndiaye, P.I., Fall, M.L., Traoré, M., Barboza, D., Ould Ely, M.C., Ba, B. and Gaye, I. (2014) Modalités d'admission des patients dans un service de réanimation en Afrique et conséquences sur l'évolution. Revue Africaine d' Anesthésiologie et de Médecine d' Urgence, 19, No. 1.

[13] Iteke, F.R., Ahuka, O.L., Mugisho, G., Iragi, M.D. and Brouh, Y. (2014) Intérêts et limites de l'utilisation des indices de gravité généralistes en réanimation des pays à ressources limitées (Congo). Revue Africaine d Anesthésiologie et de Médecine d'Urgence, 19, 10-16.

[14] Dia, N.M., Diallo, I., Manga, N.M., Diop, S.A., Fortes Deguenonvo, L., Lakhe, N.A., Ka, D., Seydi, M. and Diop, B.M. (2015) Intérêt de l'indice de gravité simplifié ambulatoire (IGSA) appliqué à des patients admis dans l'unité de soins intensifs (USI) d'un service de pathologie infectieuse à Dakar. Bulletin de la Société de Pathologie Exotique, 108, 175-180. https://doi.org/10.1007/s13149-015-0418-x

[15] Kabamba, L.N., Cowgill, K., Bondo, B., Kabyla, B. and Wembonyama, L.O. (2015) Prévalence de l'hypertension artérielle dans la population des meuniers de la ville de Lumumbashi, République Démocratique du Congo. Pan African Medical Journal, 22, 152. https://doi.org/10.11604/pamj.2015.22.152.6677 
[16] Aguèmon, A.R., Padonou, J.L., Yévègnon, S.R., Hounkpè, P.C., Madougou, S., Djagnikpo, A.K. and Atchadé, D. (2005) Traumatismes crâniens graves en réanimation au Bénin de 1998 à 2002. Annales Françaises d Anesthésie et de Réanimation, 24, 36-39. https://doi.org/10.1016/j.annfar.2004.11.011

[17] Boffelli, S., Rossi, C., Aughileri, A., Giardino, M., Carnevale, L., Messina, M., Neri, M., Langer, M. and Bertolini, G. (2006) Continuous Quality Improvement in Intensive Care Medicine: The GiViTI Margherita Project Report 2005. Minerva Anestesiologica, 72, 419-432.

[18] Le Borgne, P., Couraud, S., Herbrecht, J.E., Maestraggi, Q., Bovin, A. and Schneider, F. (2017) Clinical Characteristics and Outcome of Nonagenarians and Centenarians in a Medical ICU. Annals of Intensive Care, 7, 188 p.

[19] Moreno, R.P., Matmitz, P.G.H., Almeida, E., Jordan, B., Bauer, P., Campos, R.A., Iapichino, G., Edbrooke, D., Capuzzo, M. and Le Gall, J.R. (2005) SAPS 3 from Evaluation of the Patient to Evaluation of the Intensive Care Unit. Part 2: Development of a Prognostic Model for Hospital Mortality at ICU Admission. Intensive Care Medicine, 31, 1345-1355. https://doi.org/10.1007/s00134-005-2763-5

[20] Jungfer, F., Adande, P., Gaillard, C., Gizolme, D., Malaca, R., Nahila, M. and Tonduangu, D.K. (2008) Un exemple de dispositif multimodal d'analyse de la mortalité dans un service de Réanimation polyvalente. 10èmes Journées Internationales de la Qualité Hospitalière. 8 et 9 décembre.

[21] Gregoire, E., Claisse, G., Guiot, J., Morimont, P., Krzesinski, J.M., Mariat, C., Lambermont, B., Cavalier, E. and Delanaye, P. (2017) The Added Value of Plasma or Urinary NGAL Concentration in Clinical Practice. Annals of Intensive Care, 1, 202 p.

[22] Sik, A.H., Talik, I., Tiluch, N., Yaakoubi, S., Gharbi, R., Jaoued, O., Hassen, M.F. and Elatrous, S. (2017) Evolution of the Management and Prognosis of Patients Admitted in Intensive Care Unit for Exacerbation of Chronic Obstructive Pulmonary Disease. Annals of Intensive Care, 7, 190 p.

[23] Iteke, F.R., Ahuka, O.L., Mugisho, G. and Brouh, Y. (2014) Quelle place pour les indices de gravites pronostique des patients de réanimation? Great Lakes Medical Review, 6, 2-4.

[24] Couffin, S., Lobo, D., Prost, L.D., Mongardon, N., Dhonneur, G. and Mounier, R. (2017) Mortality Analysis of the Chronically Critically Ill Patients: An Epidemiological Prospective Study. Annals of Intensive Care, 7, 187 p.

[25] Le Gall, J.R., Lemeshow, S. and Saulnier, F. (1993) A New Simplified Acute Physiology Score (SAPS II) Based on a European/North American Multicenter Study. $J A M A, 270,2957-2963$. https://doi.org/10.1001/jama.270.24.2957

[26] Chiavone, P.A. and Sens, Y.A. (2003) Evaluation of APACHE II System among Intensive Care Patients at a Teaching Hospital. Sao Paulo Medical Journal, 121, 53-57. https://doi.org/10.1590/S1516-31802003000200004

[27] Knaus, W.A., Wagner, D.P., Draper, E.A., Zimmerman, J.E., Bergner, M., Bastos, P.G., Sirio, C.A., Murphy, D.J., Lotring, T., Damiano, A., et al. (1991) The APACHE III Prognostic System. Risk Prediction of Hospital Mortality for Critically Ill Hospitalized Adults. Chest, 100, 1619-1636. https://doi.org/10.1378/chest.100.6.1619 